\title{
International Monetary Policy Spillovers Evidence From A Time-Varying Parameter Vector Autoregression
}

\author{
Nikolaos Antonakakis ${ }^{\S, \dagger, *}$, David Gabauer $₫$, and Rangan Gupta ${ }^{\ddagger}$

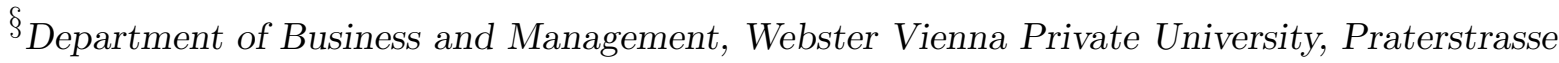 \\ 23, 1020, Vienna, Austria. Tel: +43-1-2699293-4354. Email: nikolaos.antonakakis@webster.ac.at \\ $\dagger$ Economics and Finance Subject Group, University of Portsmouth, Portsmouth Business \\ School, Portland Street, Portsmouth, PO1 3DE, United Kingdom. \\ IInstitute of Applied Statistics, Johannes Kepler University, Altenbergerstraße 69, 4040 Linz, \\ Austria. \\ ${ }^{\ddagger}$ Department of Economics, University of Pretoria, Pretoria, 0002, South Africa. \\ *Corresponding Author
}

\begin{abstract}
This study examines the transmission of international monetary policy shocks across developed economies based on a Bayesian time-varying parameter vector autoregressive (TVP-VAR) connectedness methodology. The analysis is based on daily shadow short rates over the period of January 2, 1995 to December 20, 2018. The empirical findings suggest that the magnitude of international monetary policy spillovers behaves heterogeneously over time, with unprecedented heights reached during the Great Recession of 2009, suggesting potential gains from unconventional monetary policy coordination. In addition, the results indicate that the dominant transmitters of international monetary policy shocks are the Euro Area and the US, while Japan and the UK are the dominant receivers of shocks. Our results are robust to alternative experimentations in terms of estimation and prior choices used to estimate the TVP-VAR.

Keywords: Monetary Policy Spillovers; Financial Transmission; Dynamic Connectedness, TVP-VAR

JEL codes: C32; C50; E52
\end{abstract}




\section{Introduction}

The issue of monetary policy spillovers can be traced as far back as to the 18th century in David Hume's Essays, Moral, Political, and Literary (Coeuré, 2016). Theoretical models have rigorously analyzed the international spillovers of monetary policy, and reviewed the case for and against monetary policy coordination since the mid-1980s (see Taylor, 2013, for a detailed review of this literature). In general, as noted by Engel (2016), this literature tends to point towards limited spillovers, with the desirability of cooperation across monetary authorities being highly model specific, and some potentially important shocks causing the propagation poorly understood.

From a political economic perspective, the complexity of cooperation due to legal and institutional differences is also believed to prevent cooperation (Ostry and Ghosh, 2016). In the wake of recent Global Financial Crisis (2009), Cook and Devereux (2016) focused on the effects of the Zero Lower Bound (ZLB) and unconventional monetary policy actions (such as Quantitative Easing, QE). Their findings suggest that spillovers, during the ZLB period, can be larger than in 'normal times' illustrating gains from monetary policy coordination. In sum, a relevant empirical hypothesis that needs to be tested is: Whether monetary policy spillovers are higher during episodes of unconventional monetary policy when compared to normal times? This is exactly the question we aim to answer by investigating daily shadow short rate (SSR) spillovers across the United States (US), the Euro Area, Japan and the United Kingdom (UK) employing the dynamic connectedness approach (Diebold and Ylmaz, 2014) with an underlying time-varying parameter vecto autoregressive (TVP-VAR) model (Koop and Korobilis, 2014). 
Naturally, the interest in monetary policy spillovers has already be addressed by multiple researchers. One study that is similar to ours is conducted by Claus et al. (2016), whereby the authors used a constant parameter latent factor model. Their results indicate that there is significant evidence of spillovers across monetary policies between the US and Japan, with the effect being stronger during unconventional monetary policy regimes. On another note, Liu et al. (2018) examine whether monetary policy decisions of major central banks affect each other. In more detail this study analyzes the interaction between the US, UK and Euro Area using quarterly data. Hereby, we want to refer to Nakamura and Steinsson $(2018 \mathrm{a}, \mathrm{b})$ who stress out that it is essential to use high-frequency data to receive cleaner monetary policy dynamics. Among the many, Belke and Dubova (2018) is closest to our study. It is also analysing SSRs spillovers across global asset markets using the rolling-window version of the connectedness approach Diebold and Yllmaz (2012). However, as we indicate later the rolling-window framework has several severe limitations relative to the time-varying parameter method we are proposing. Very recently this strand of literature - analyzing interest rate, as well as bond yields, spillovers - has become quite popular, see for example, Belke et al. (2018); Galariotis et al. (2018); Cronin (2014); Garcia-de Andoain and Kremer (2017); Berisha et al. (2018); Sowmya et al. (2016); Lee et al. (2016).

As indicated above, in the wake of Global Financial Crisis (2009) and the ZLB situation that ensued thereafter, central banks in the analyzed economies pursued unconventional monetary policies such as Quantitative Easing which involves a multitude of measures like large-scale asset purchases, maturity extension programs, and efforts of forward guidance 
in order to manage expectations of a prolonged period of low policy rates (Tillmann, 2016). But understandably, to compare across the conventional and unconventional regimes of monetary policy decisions, we would need a common metric capturing the stance of monetary policy. We circumvent this apparent empirical difficulty by considering the Shadow Short Rate (SSR), which is the nominal interest rate that would prevail in the absence of its effective lower bound, with it derived by modelling the term structure of the yield curve.

The main advantage of the SSR is that it is not constrained by the ZLB and thus allows us to combine the monetary policy instrument data from the ZLB period with the data from the non-ZLB era. For our analysis we rely on the daily SSR data, as developed by Krippner (2013), over the period of January 2, 1995 to December 20, 2018. Note that, alternative measures of the SSR for the US, the UK and the Euro Area have also been developed by Wu and Xia (2016). However, besides being only available at monthly frequency and unavailable for Japan which also witnessed the ZLB situation, the SSR estimates derived by Krippner (2013) are more robust as shown by Krippner (2017). In addition, given the large literature that exists on the impact of domestic and international (conventional and unconventional) monetary policy on macroeconomic variables are primarily at monthly or quarterly frequency (see, Claessens et al., 2016, for a detailed literature review in this regard), knowledge of monetary policy spillovers at a higher frequency is likely to be more beneficial to policy makers in determining the direction in which the economy is headed in the future (Nakamura and Steinsson, 2018a,b). 
To answer whether monetary policy spillovers are higher during episodes of unconventional monetary policy when compared to normal times, we are using a full-fledged time-varying parameter vector autoregressive (TVP-VAR) model introduced by Koop and Korobilis (2014). Combining this framework with the popular dynamic connectedness approach Diebold and Yilmaz (2012) allows us to investigate spillovers across shadow short rates over time more. The TVP-VAR design improves the methodology provided by Diebold and Yılmaz (2012) substantially, since (i) there is no need to arbitrarily set the rolling window-size, (ii) there is no loss of observations, and (iii) it is not sensitive to outliers (Antonakakis and Gabauer, 2017; Antonakakis et al., 2018; Gabauer and Gupta, 2018; Korobilis and Yilmaz, 2018).

To the best of our knowledge, this is the first attempt to compare international monetary policy spillovers across conventional and unconventional monetary policy regimes for four developed economies using a TVP-VAR based connectedness approach.

The results of our empirical analysis suggest that, the transmission of international monetary policy shocks is an important source of domestic monetary policy fluctuations. Moreover, the magnitude of international monetary policy spillovers behaves heterogeneously overtime, with unprecedented heights reached during the Great Recession (2009). In addition, the dominant transmitters of international monetary policy shocks are the Euro Area and the US, while Japan and the UK are the dominant receivers of international monetary policy shocks. Interestingly enough, international monetary policy shocks originating from the US are the largest during the zero lower bound and the related unconventional monetary policy actions era, indicating potential gains from monetary 
policy coordination.

The rest of the paper is organized as follows: Section 2 lays out the basics of the methodology, while Section 3 presents the data and discusses the results. Finally, Section 4 concludes this study.

\section{Methodology}

\subsection{TVP-VAR-Based Dynamic Connectedness Approach}

In order to explore the transmission mechanism of monetary policy in a time-varying fashion, we use the TVP-VAR methodology of Koop and Korobilis (2014) and combine it with the connectedness approach of Diebold and Yllmaz (2014). This framework allows the variances to vary over time via a Kalman Filter estimation which relies on decay factors. By doing so, the TVP-VAR approach overcomes the burden of the often arbitrarily chosen rolling-window-size, that could lead to very erratic or flattened parameters, and loss of valuable observations (Antonakakis and Gabauer, 2017; Antonakakis et al., 2018; Gabauer and Gupta, 2018; Korobilis and Yilmaz, 2018).

In particular, the Bayesian information criterion (BIC) suggests a TVP-VAR $(1)^{1}$ model which can be written as follows,

$$
\begin{aligned}
\Delta \boldsymbol{x}_{t} & =\boldsymbol{\beta}_{t} \Delta \boldsymbol{x}_{t-1}+\boldsymbol{\epsilon}_{t} & \boldsymbol{\epsilon}_{t} & \sim N\left(\mathbf{0}, \boldsymbol{\Sigma}_{t}\right) \\
\operatorname{vec}\left(\boldsymbol{\beta}_{t}\right) & =\operatorname{vec}\left(\boldsymbol{\beta}_{t-1}\right)+\boldsymbol{\nu}_{t} & \boldsymbol{\nu}_{t} & \sim N\left(\mathbf{0}, \boldsymbol{R}_{t}\right)
\end{aligned}
$$

\footnotetext{
${ }^{1}$ Due to numerical stability we decided to implement decay factors in the Kalman Filter algorithm. The choice of decay factors resembles the choice of priors in general and depends on the expected amount of time-variation in the parameters. Since this study analyzes daily data - oppposed to Koop and Korobilis (2014) - the benchmark model is based on $\kappa_{1}=0.99$ and $\kappa_{2}=0.99$.
} 
where $\Delta \boldsymbol{x}_{t}, \Delta \boldsymbol{x}_{t-1}$ and $\boldsymbol{\epsilon}_{t}$ are $N \times 1$ dimensional vector, $\boldsymbol{\beta}_{t}$ and $\boldsymbol{\Sigma}_{t}$ are $N \times N$ dimensional matrices. The parameters $\operatorname{vec}\left(\boldsymbol{\beta}_{t}\right)$ and $\boldsymbol{\nu}_{t}$ are $N^{2} \times 1$ dimensional vectors whereas $\boldsymbol{R}_{t}$ is an $N^{2} \times N^{2}$ dimensional matrix.

After we have estimated the time-varying parameters, we need to transform the TVPVAR to a TVP-VMA using the Wold representation theorem, $\Delta \boldsymbol{x}_{t}=\sum_{i=1}^{p} \boldsymbol{\beta}_{i t} \Delta \boldsymbol{x}_{t-i}+\boldsymbol{\epsilon}_{t}=$ $\sum_{j=1}^{\infty} \boldsymbol{\Lambda}_{j t} \boldsymbol{\epsilon}_{t-j}+\boldsymbol{\epsilon}_{t}$. In a next step, the TVP-VMA coefficients are extracted to calculate the generalized forecast error variance decomposition (GFEVD) (Koop et al., 1996; Pesaran and Shin, 1998) on which the dynamic connectedness framework is built on.

The (unscaled) GFEVD, $\phi_{i j, t}^{g}(J)$ - representing the pairwise directional connectedness from $j$ to $i$ which in turn is the influence variable $j$ has on variable $i$ in terms of its forecast error variance share - is defined as follows:

$$
\phi_{i j, t}^{g}(J)=\frac{\sum_{i i, t}^{-1} \sum_{t=1}^{J-1}\left(\boldsymbol{\iota}_{i}^{\prime} \boldsymbol{\Lambda}_{t} \boldsymbol{\Sigma}_{t} \boldsymbol{\iota}_{j}\right)^{2}}{\sum_{j=1}^{N} \sum_{t=1}^{J-1}\left(\boldsymbol{\iota}_{i} \boldsymbol{\Lambda}_{t} \boldsymbol{\Sigma}_{t} \boldsymbol{\Lambda}_{t}^{\prime} \iota_{i}\right)} \quad \tilde{\phi}_{i j, t}^{g}(J)=\frac{\phi_{i j, t}^{g}(J)}{\sum_{j=1}^{N} \phi_{i j, t}^{g}(J)}
$$

with $\sum_{j=1}^{N} \tilde{\phi}_{i j, t}^{g}(J)=1$ and $\sum_{i, j=1}^{N} \tilde{\phi}_{i j, t}^{g}(J)=N$, where $J$ represents the forecast horizon and $\boldsymbol{\iota}_{i}$ a selection vector with a one on the $i$ th position and zero otherwise. Using the GFEVD, we construct the total connectedness index by

$$
C_{t}^{g}(J)=1-N^{-1} \sum_{i=1}^{N} \tilde{\phi}_{i i, t}^{g}(J)
$$

This connectedness approach shows how a shock in one variable spills over to other variables. First, we look at the case where variable $i$ transmits its shock to all other 
variables $j$, called total directional connectedness to others,

$$
C_{i \rightarrow j, t}^{g}(J)=\sum_{j=1, i \neq j}^{N} \tilde{\phi}_{j i, t}^{g}(J)
$$

Second, we calculate the directional connectedness variable $i$ receives from variables $j$, called total directional connectedness from others and defined as

$$
C_{i \leftarrow j, t}^{g}(J)=\sum_{j=1, i \neq j}^{N} \tilde{\phi}_{i j, t}^{g}(J)
$$

Finally, we subtract the total directional connectedness to others from the total directional connectedness from others to obtain the net total directional connectedness, which can be interpreted as variable $i$ influence on the analyzed network.

$$
C_{i, t}^{g}=C_{i \rightarrow j, t}^{g}(J)-C_{i \leftarrow j, t}^{g}(J)
$$

If the net total directional connectedness of variable $i$ is positive, it means that variable $i$ influences the network more than being influenced by it. By contrast, if the net total directional connectedness is negative, it means that variable $i$ is driven by the network.

Since the net total directional connectedness is an aggregated measure and sometimes masks important underlying dynamics we are interested in the net pairwise directional connectedness (NPDC). This measure provides us with information about the bilateral transmission process between variable $i$ and variable $j$ :

$$
N P D C_{i j}(J)=\tilde{\phi}_{j i, t}(J)-\tilde{\phi}_{i j, t}(J)
$$

If $N P D C_{i j}(J)>0\left(N P D C_{i j}(J)<0\right)$ variable $i$ is driving (driven by) variable $j$. 


\section{Data and Empirical Results}

\subsection{Data}

With policy rates in the ZLB range for a prolonged period of time post the financial crisis, posed a great challenge to empirical researchers dealing with monetary policy to find alternative quantitative measures that are able to describe monetary policy at the ZLB. One such measure is the Shadow Short Rate (SSR). The SSR used in this paper is developed by Krippner (2013), based on a two-factor model of term-structure, at a daily frequency for the four economies of our concern, and is available for download from the website of the Reserve Bank of New Zealand. ${ }^{2}$ The two-factor yield curve-based framework developed by Krippner (2013) essentially removes the effect that the option to invest in physical currency (at an interest rate of zero) has on yield curves, resulting in a hypothetical "shadow yield curve" that would exist if physical currency were not available. The process allows one to answer the question: "What policy rate would generate the observed yield curve if the policy rate could be taken negative?" The "shadow policy rate" generated in this manner, therefore, provides a measure of the monetary policy stance after the actual policy rate reaches zero.

We collect daily observations of the SSRs for the United States, the Euro Area, Japan and the United Kingdom over the period January 2, 1995 to December 20, 2018. The sample size is purely driven by its availability. Figure 1 plots the first differenced shadow short $\operatorname{rates}^{3}, \Delta x_{i t-1}=x_{i t}-x_{i t-1}$.

\footnotetext{
${ }^{2}$ Data can be downloaded from the Reserve Bank of New Zealand.

${ }^{3}$ Transformation is necessary since according to the ERS unit-root test all shadow short rates have been non-stationary.
} 
[Insert Figure 1 around here]

The summary statistics of the transformed series are presented in Table 1 . We find that all series are significantly skewed whereas all except for the US are right skewed. In addition, all variables are leptokurtic, not normally distributed and stationary on the $1 \%$ signifcance level. Suggestive evidence is shown that all series are autocorrelated and exhibit ARCH errors which supports choosing a TVP-VAR model with time-varying covariances.

[Insert Table 1 around here]

\subsection{Empirical Results}

In Table 2, we report the averaged dynamic connectedness measures for each series. First, we want to focus on the TVP-VAR-based connectedness results. Summarizing the information in Table 2, we observe that own-country monetary policy spillovers explain the highest share of forecast error variance, as the diagonal elements receive higher values compared to the off-diagonal elements. For instance, the Euro Area explain $16.4 \%$ and $17.2 \%$ of the 10-days-ahead forecast error variance of the US and the UK, respectively, but only $4.5 \%$ in Japan. Contrary, the US, UK and Japan explain 10.7\%, 3.5\% and 2.0\% of the Euro Area's 10-days-ahead forecast error variance. This in turn means that Europe is a net pairwise transmitter to the US, UK and Japan which in turn means that it is the main net transmitter of shocks. Moreover, the most important net transmitters of shocks are the Euro Area followed by the US, while UK and Japan are the main net receivers of shocks throught the period of analysis. According to the total connectedness index (TCI) 
the average influence all other variables have on one variable's forecast error variance throughout time is $19.2 \%$. Put differently, monetary policy actions are not independent from each other; the average influence of a central bank's action is approximately $20 \%$. Even though this value is not very large it shows that the transmission of international monetary policy shocks is an important source of domestic monetary policy fluctuations.

[Insert Table 2 around here]

We now turn our attention to the interpretation of the spillover plots based on the time-varying estimates of the various connectedness measures. Figure 2 presents the results for the dynamic total connectedness (index). We observe a large variation in the total connectedness index, which turns out very responsive to (extreme) economic events such as the Asian Financial Crisis (1997), the introduction of the Euro (2002), the Great Recession (2009) and the subsequent European sovereign debt crisis (2012). In particular, monetary policy spillovers reached unprecedented heights during the Great Recession, a period characterized by intense unconventional monetary policy interventions primarily. Note that this dynamics provide evidence that the (static) TCI is masking specific episodes (i.e., economic shocks) that have had a distinct impact on its interconnectedness. This points out that analyzing the time-varying behavior of connectedness measures is of main importance to understand the monetary policy transmission mechanism in detail.

[Insert Figure 2 around here]

Figure 3 presents the dynamic total directional connectedness of monetary policy shocks to others, while Figure 4 presents the dynamic total directional connectedness of 
monetary policy shocks from others. According to these two figures, directional spillovers from or to each series range between $0 \%$ to $25 \%$ and are of bilateral nature. Nevertheless, they behave rather heterogeneously overtime and follow a similar pattern as the one found for the dynamic total connectedness.

As we can see in Figure 3, the US and the Euro Area show significant time-varying transmission pattern. In the US, we see that the transmission of shocks - during times of conventional monetary policy - to others increased during the Dotcom crisis (2001) and when the investment bank, Lehman Brothers, went bankrupt in 2008 and the Federal Reserve Bank started to buy $\$ 600$ billion in mortgage-backed securities ${ }^{4}$. In summer 2011, the second round of quantitative easing has been executed and the Federal Reserve Bank started to buy every month Treasury notes which are worth $\$ 30$ billion. The last and third round of quantitative easing was announced in September 2012 and should last until the end of 2014. This is exactly the point in time when the US total directional connectedness decreases substantially.

Similar patterns can be observed in the Euro Area whereas in addition we see an increase in its shock tranmission when the Euro was introduced in 2002 and during the European governmental debt crisis (2012) when the European Central Bank started to buy sovereign bonds of highly indebted countries. In case of Japan, we observe that its largest value has been reached in 1995 which marks the time when Japan hit the ZLB and the Japanese two lost decades began. The UK has like Japan very limited influence on other's monetary policy actions.

\footnotetext{
${ }^{4}$ Federal Reserve. 2008 Monetary Policy Releases
} 
[Insert Figure 3 around here]

Figure 4 depicts the amount of shocks received by each country. As we can see the US receives constantly more shocks during the period of conventional monetary policy than during the time of unconventional monetary policy. Nevertheless, we have seen previously that the US tranmission of shocks has increased substantially indicating its gain in terms of monetary policy efficiency. Interestingly enough, the Euro Area has become more independent after the introduction of Euro. This could show the importance the Euro gained on international financial markets until the European governmental debt crisis (2012) when some European countries suffered from their unsustainable governmental debts. In addition, the results are suggesting that Japan has also not be influenced by the monetary policy actions of others whereas the UK significantly receives more shocks than it is transmitting.

[Insert Figure 4 around here]

A similar picture emerges when looking at the dynamic net total directional connectedness which is depicted in Figure 5. We see that Japan and the UK are mostly net receivers of shocks during our sample period whereas the UK is receiving much more than Japan. The Euro Area is a net transmitter of monetary policy shocks since the introduction of Euro (2002) and up to the Great Recession (2009), and from 2012 onward, while a net receiver of monetary policy shocks in the remaining periods. Finally, the US is on the transmitting end from 1995 to 2000 and from the period of the Great Recession (2009) onward, and on the receiving ends since the introduction of the Euro and up to the 
onset of the the Great Recession (2009). The change in the US - from net receiver to net transmitter - could be caused by the introduction of unconventional monetary policy.

[Insert Figure 5 around here]

Finally, we focus on the net pairwise directional connectedness of shocks - spillovers across pairs of countries - which are presented in Figure 6, we observe the following empirical regularities. First, spillovers are of greater magnitude between the Euro Area, UK and the US, compared to pairs of countries where Japan is included. Hence, Japan's monetary policy seems not to influence or being influenced by the others and is thus rather independent. The Euro Area seems to be the net pairwise transmitter of shocks to the UK (since the introduction of the Euro) and to the US (from the inception of the (Euro and up to the Great Recession), while the US is the dominant net transmitter of monetary policy shocks to the UK. This got even more pronounced after the Great Recession (2009).

[Insert Figure 6 around here]

In an attempt to examine whether the transmission of monetary policy spillovers differs between periods of conventional monetary policy and unconventional monetary policy (zero lower bound), we split the sample into two subperiods: (a) from January 2, 1995 to November 30, 2008 (conventional US monetary policy) and (b) December 1, 2008 to December 20, 2018 (unconventional US monetary policy, with the SSR turning negative for the first time on the starting date of the sub-sample). 
The results of this analysis are reported in Table 3. According to these results, we observe that, despite that overall monetary policy spillovers do not change dramatically between the unconventional period and conventional era, as indicated by both TCIs, the US is the dominant transmitter of shocks during the unconventional monetary policy era, while a net receiver of shocks in the conventional monetary policy era. In other words, the introduction of quantitative easing in the US can be associated with a significant increase in international monetary policy spillovers originating from the US. In particular, monetary policy shocks in the US explain $13.8 \%, 18.0 \%$ and $3.3 \%$ of the forecast error variance of monetary policy shocks in the Euro Area, the UK and Japan, respectively, whereas during the era of conventional monetary policy, the US influences the forecast error variance of the Euro Area, Japan and the UK by $8.4 \%, 6.4 \%$ and $2.0 \%$, respectively. It is also important to know that not only the US transmission of shocks increased also the impact of others to the US decreased. We find that the US has been influenced by the Euro Area and the UK by $22.1 \%$ and $4.6 \%$ prior to the US unconventional monetary policy whereas after its introduction the influences decreased to $8.5 \%$ and $2.0 \%$. The influence of Japan on the US seems to stay rather constant.

Before the introduction of unconventional policy measures in the US, the Euro Area was the dominant net transmitter of shocks followed by the US. However, with the introduction of unconventional monetary policy this pattern changed and the US became the main net transmitter of international monetary policy shocks. This findings are in-line with the study of Cook and Devereux (2016) who find that spillovers, caused by unconventional monetary policy, can be larger compared to those during 'normal times'. Interestingly 
enough, unconventional monetary policy cannot only lead to an increase in its influence to others it is also decreased the influence of others which makes a country's monetary policy actions more independent from others. Naturally, it would be interesting to know how the transmission mechanism would change when all analyzed countries are using unconventional instead of conventional monetary policy.

[Insert Table 3 around here]

These results have important policy implications in the sense that, during episodes of severe crises the design of monetary policy could reduce the impact other countries' monetary policy has on domestic monetary policy. In other words, there could be possible gains from coordinating monetary policy decisions, especially in the wake of extraordinary situations like those observed during the recent global financial and the European debt crises.

\subsection{Robustness Checks}

In this segment, we carry out some robustness analyses. In addition to the TVP-VARbased connectedness results, we also present 200-days rolling-window VAR and Quantile VAR (QVAR) results. Different window sizes were used, however the 200-observations rolling window showed close similarities with the TVP-VAR results and is also used as a benchmark model in Diebold and Yllmaz (2009, 2012). Since a VAR model can be estimated as an equation-by-equation Ordinary Least Squares (OLS) model, it is a conditional mean-based procedure, and hence is sensitive to outliers. If we estimate every equation by a quantile regression (or via least absolute deviation (LAD) regression), we 
focus on the conditional median-based estimation and hence, can likely overcome the outlier sensitivity problem of the VAR model. Even though the dynamics of all three models look very similar, a closer look reveals that the TVP-VAR model adjusts faster than its alternatives as stressed in Antonakakis and Gabauer (2017) and Korobilis and Yilmaz (2018). This is essential when it comes to the prediction of the interconnectedness and hence risk of the analyzed system. If we only want to track the evolution during crises, this time delay is not too problematic. However, the outlier sensitivity problem of the VAR model leads to incorrect results which become more obvious in the unconventional monetary policy regime.

Figure 7 points out three different sensitivity analyses. Panel A illustrates the differences in the dynamic total connectedness by adjusting the forecast horizon. Interestingly, we see that after 2011 the differences in the metrics increase substantially. This can be explained by the fact that the network is more persistent during unconventional monetary policy which in turn illustrates the increase in its effectiveness. Furthermore, the differences in the dynamics seems to flatten out until the end of the period which could be a result in the switch of the US back to conventional monetary policy.

In addition in Panel B, we show that the prior specification is only influencing the few observations until they are squeezed out of the system which in turn leads to the convergence of the TVP-VAR dynamic connectedness results.

Finally, Panel C illustrates the variation of the dynamic connectedness when we allow the decay factor of the variance-covariance to assume different values. Herein, the decay factor of the VAR coefficient is held constant at 0.99 since it is very implausible 
that the relationship across variables change from one day to another by more than 1\%. Interestingly, we find that the grey area illustrating the variation of the dynamic connectedness by estimating different TVP-VAR specifications does not including the dynamic connectedness of the VAR and QVAR values. This marks again the time delay issue of the rolling-window models. Notably, the VAR model behaves substantially different than the other two models after 2012, whereas the TVP-VAR and the QVAR model share similar comovements.

\section{Conclusion}

In this study, we examined the international transmission of monetary policy shocks across the US, the Euro Area, UK and Japan over the period of 1995 to 2018 based on a TVPVAR methodology estimated using Bayesian methods to prevent overparameterization. Given that our period of analysis covers the zero lower bound situation, we use the shadow short rate instead of the standard monetary policy instrument. The shadow short rate, generated from a factor-based model of the term-structure, provides a measure of the monetary policy stance after the actual policy rate reaches zero during the unconventional regime of monetary policy, with it simultaneously mimicking the conventional monetary policy regime.

The results of our empirical analysis suggest that, the transmission of international monetary policy shocks is an important source of domestic monetary policy fluctuations. Moreover, the magnitude of international monetary policy spillovers behaves heterogeneously overtime, with peaks reached during the Great Recession of 2009. Further, the 
dominant transmitters of international monetary policy shocks are the Euro Area and the US, while Japan and the UK are the dominant receivers of international monetary policy shocks. Interestingly, international monetary policy shocks originating from the US are the largest during the zero lower bound and the related unconventional monetary policy actions era, which in turn, is indicative of the potential gains from monetary policy coordination.

\section{References}

Anscombe, F. J. and Glynn, W. J. (1983). Distribution of the kurtosis statistic b2 for normal samples. Biometrika, 70(1):227-234.

Antonakakis, N. and Gabauer, D. (2017). Refined Measures of Dynamic Connectedness based on TVP-VAR. MPRA Paper 78282, University Library of Munich, Germany.

Antonakakis, N., Gabauer, D., Gupta, R., and Plakandaras, V. (2018). Dynamic connectedness of uncertainty across developed economies: A time-varying approach. Economics Letters, 166:63-75.

Belke, A. and Dubova, I. (2018). International spillovers in global asset markets. Economic Systems, 42(1):3-17.

Belke, A., Dubova, I., and Volz, U. (2018). Bond yield spillovers from major advanced economies to emerging Asia. Pacific Economic Review, 23(1):109-126.

Berisha, E., Meszaros, J., and Olson, E. (2018). Income inequality, equities, household debt, and interest rates: Evidence from a century of data. Journal of International Money and Finance, 80:1-14.

Claessens, S., Stracca, L., and Warnock, F. E. (2016). International Dimensions of Conventional and Unconventional Monetary Policy. Journal of International Money and Finance, 67:1-7.

Claus, E., Claus, I., and Krippner, L. (2016). Monetary Policy Spillovers Across the Pacific when Interest Rates are at the Zero Lower Bound. Reserve Bank of New Zealand Discussion Paper Series DP2016/08, Reserve Bank of New Zealand.

Coeuré, B. (2016). The Internationalisation of Monetary Policy. Journal of International Money and Finance, 67(C):8-12.

Cook, D. and Devereux, M. B. (2016). Exchange Rate Flexibility under the Zero Lower Bound. Journal of International Economics, 101(C):52-69.

Cronin, D. (2014). The interaction between money and asset markets: A spillover index approach. Journal of Macroeconomics, 39:185-202. 
D'Agostino, R. B. (1970). Transformation to normality of the null distribution of g1. Biometrika, 57(3):679-681.

Diebold, F. X. and Yılmaz, K. (2009). Measuring financial asset return and volatility spillovers, with application to global equity markets. Economic Journal, 119(534):158171.

Diebold, F. X. and Yllmaz, K. (2012). Better to Give than to Receive: Predictive Directional Measurement of Volatility Spillovers. International Journal of Forecasting, 28(1):57-66.

Diebold, F. X. and Yılmaz, K. (2014). On the Network Topology of Variance Decompositions: Measuring the Connectedness of Financial Firms. Journal of Econometrics, 182(1):119-134.

Engel, C. (2016). International Coordination of Central Bank Policy. Journal of International Money and Finance, 67(C):13-24.

Fisher, T. J. and Gallagher, C. M. (2012). New weighted portmanteau statistics for time series goodness of fit testing. Journal of the American Statistical Association, 107(498):777-787.

Gabauer, D. and Gupta, R. (2018). On the transmission mechanism of country-specific and international economic uncertainty spillovers: Evidence from a TVP-VAR connectedness decomposition approach. Economics Letters, 171:63 - 71.

Galariotis, E., Makrichoriti, P., and Spyrou, S. (2018). The impact of conventional and unconventional monetary policy on expectations and sentiment. Journal of Banking $\mathscr{E}$ Finance, 86:1-20.

Garcia-de Andoain, C. and Kremer, M. (2017). Beyond spreads: Measuring sovereign market stress in the Euro Area. Economics Letters, 159:153-156.

Jarque, C. M. and Bera, A. K. (1980). Efficient tests for normality, homoscedasticity and serial independence of regression residuals. Economics Letters, 6(3):255-259.

Koop, G. and Korobilis, D. (2014). A New Index of Financial Conditions. European Economic Review, 71:101-116.

Koop, G., Pesaran, M. H., and Potter, S. M. (1996). Impulse Response Analysis in Nonlinear Multivariate Models. Journal of Econometrics, 74(1):119-147.

Korobilis, D. and Yilmaz, K. (2018). Measuring Dynamic Connectedness with Large Bayesian VAR Models. Technical report, University of Essex, Essex Business School.

Krippner, L. (2013). A Tractable Framework for Zero Lower Bound Gaussian Term Structure Models. Reserve Bank of New Zealand Discussion Paper Series DP2013/02, Reserve Bank of New Zealand.

Krippner, L. (2017). A comment on Wu and Xia (2016) from a Macroeconomic Perspective. CAMA Working Papers 2017-41, Centre for Applied Macroeconomic Analysis, Crawford School of Public Policy, The Australian National University.

Lee, H.-C., Hsu, C.-H., and Chien, C.-Y. (2016). Spillovers of international interest rate swap markets and stock market volatility. Managerial Finance, 42(10):943-962.

Liu, L., Matthes, C., and Petrova, K. (2018). Monetary Policy across Space and Time.

Nakamura, E. and Steinsson, J. (2018a). High frequency identification of monetary non-neutrality: The information effect. Quarterly Journal of Economics. 
Nakamura, E. and Steinsson, J. (2018b). Identification in macroeconomics. Journal of Economic Perspectives, 32(3):59-86.

Ostry, J. D. and Ghosh, A. R. (2016). On the Obstacles to International Policy Coordination. Journal of International Money and Finance, 67(C):25-40.

Pesaran, H. H. and Shin, Y. (1998). Generalized Impulse Response Analysis in Linear Multivariate Models. Economics Letters, 58(1):17-29.

Sowmya, S., Prasanna, K., and Bhaduri, S. (2016). Linkages in the term structure of interest rates across sovereign bond markets. Emerging Markets Review, 27:118-139.

Stock, J., Elliott, G., and Rothenberg, T. (1996). Efficient tests for an autoregressive unit root. Econometrica, 64(4):813-836.

Taylor, J. B. (2013). International Monetary Policy Coordination: Past, Present and Future. BIS Working Papers 437, Bank for International Settlements.

Tillmann, P. (2016). Unconventional Monetary Policy and the Spillovers to Emerging Markets. Journal of International Money and Finance, 66:136-156.

Wu, J. C. and Xia, F. D. (2016). Measuring the Macroeconomic Impact of Monetary Policy at the Zero Lower Bound. Journal of Money, Credit and Banking, 48(2-3):253-291. 
Figure 1: First Differences Shadow Short Rates
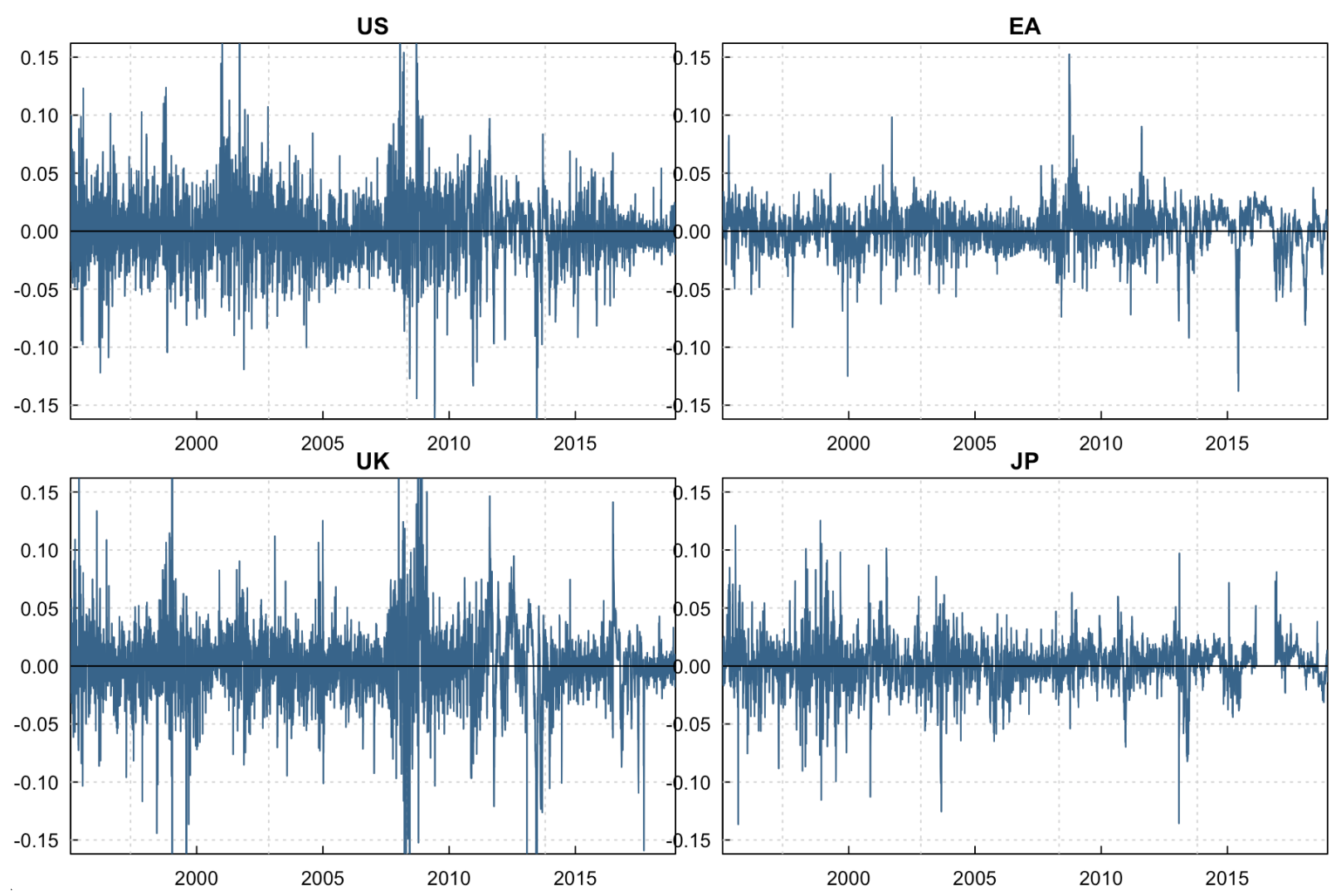

Figure 2: Dynamic Total Connectedness

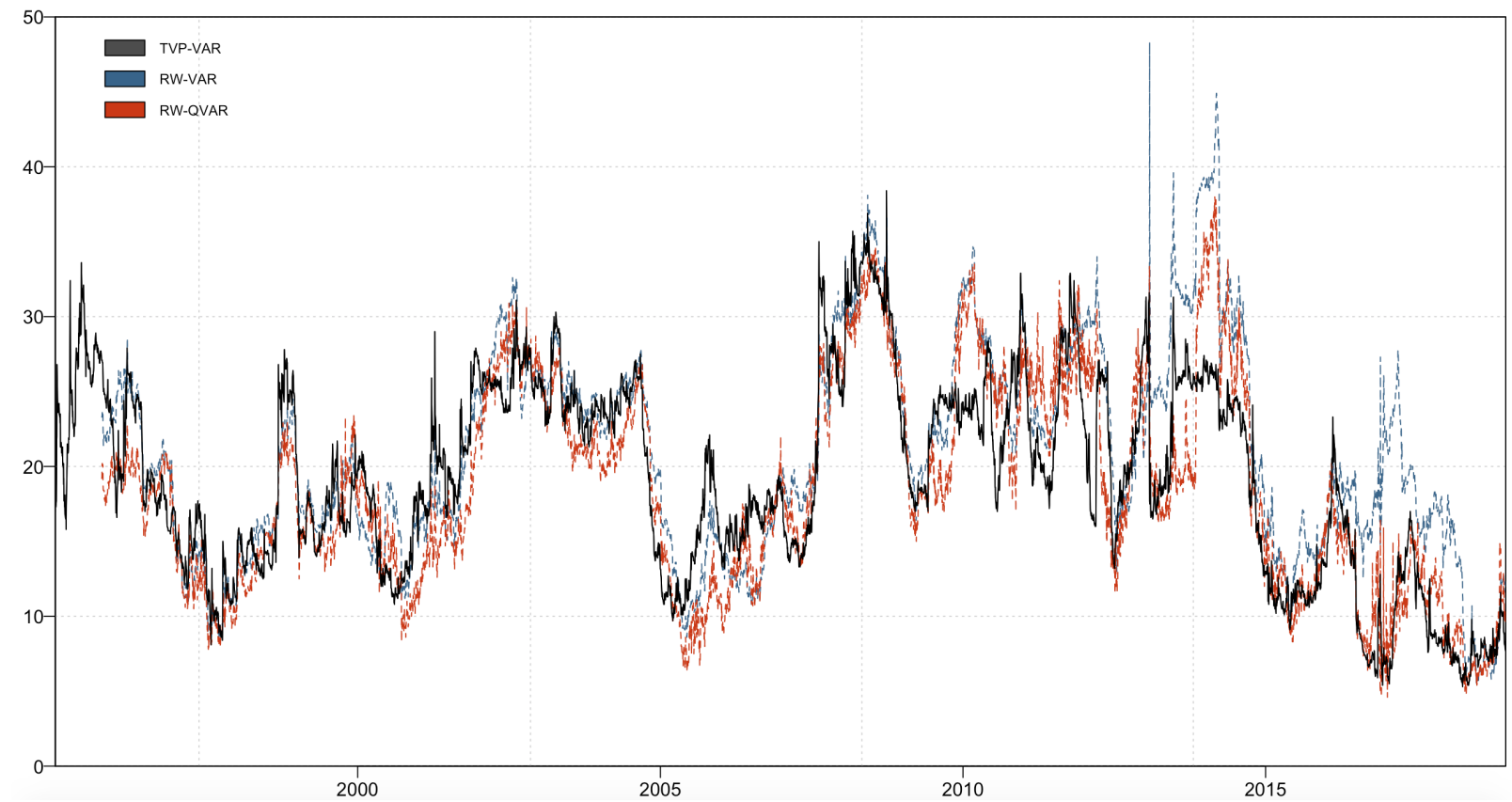


Figure 3: Total Directional Connectedness TO Others
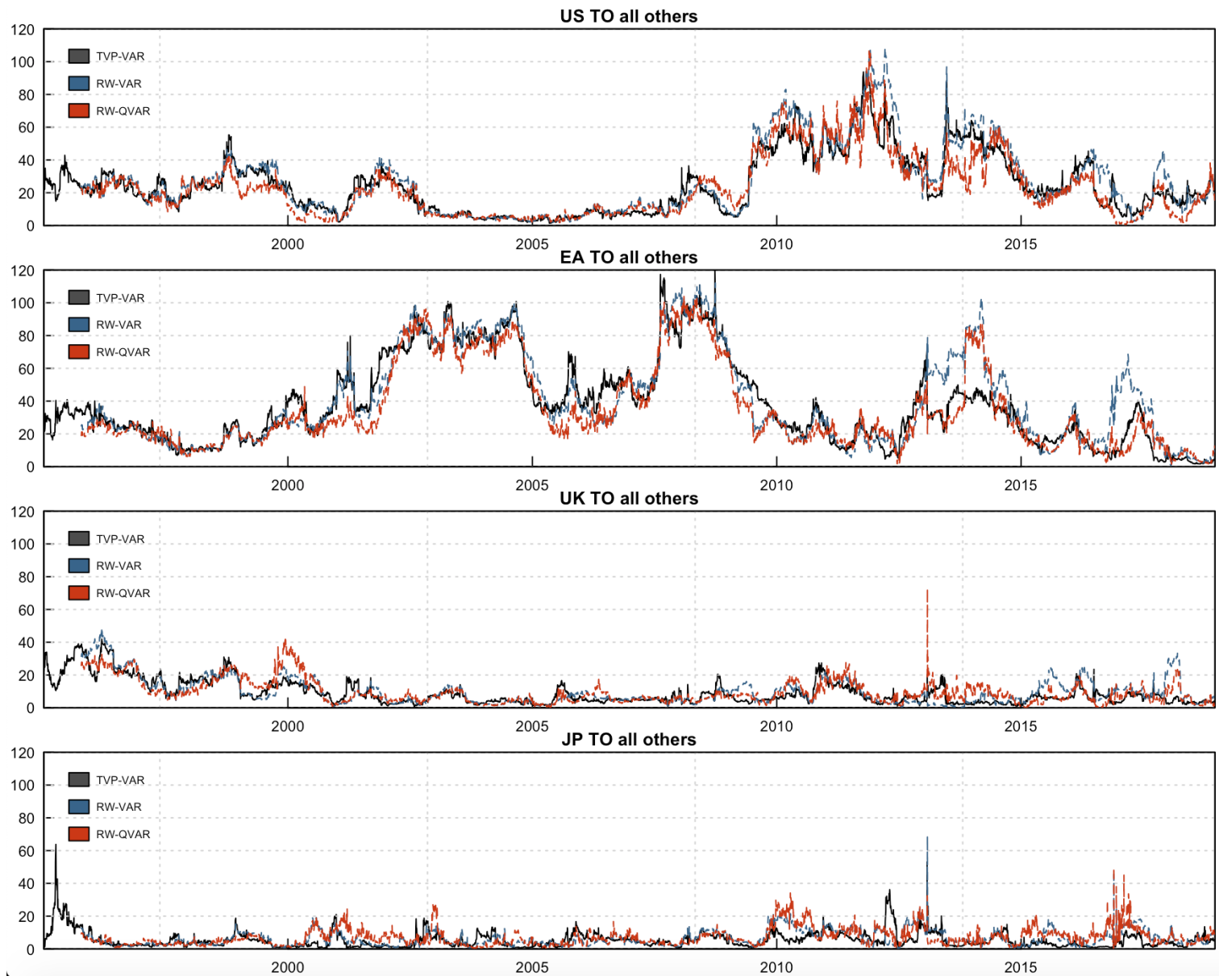

Figure 4: Total Directional Connectedness FROM Others
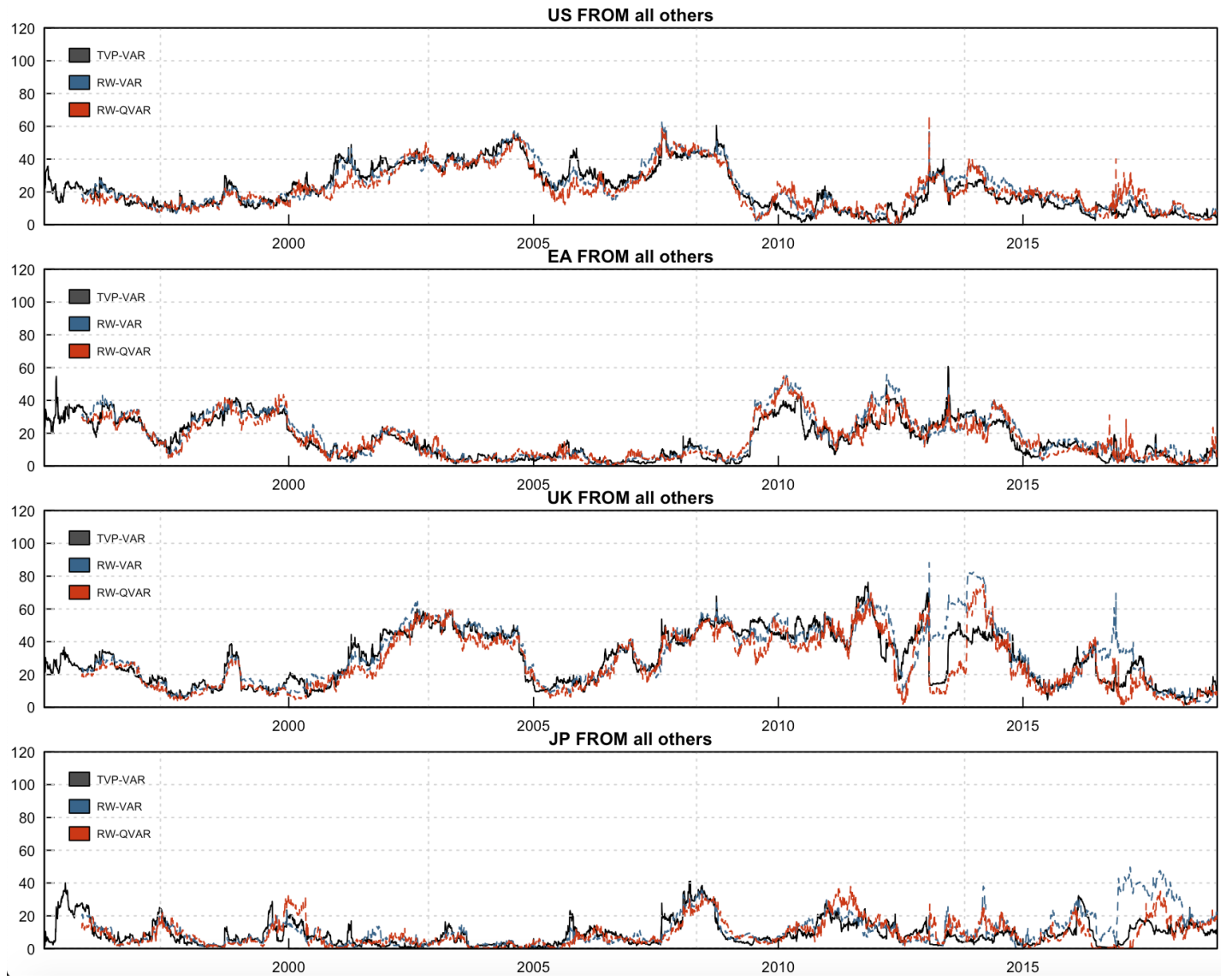
Figure 5: Net Total Directional Connectedness

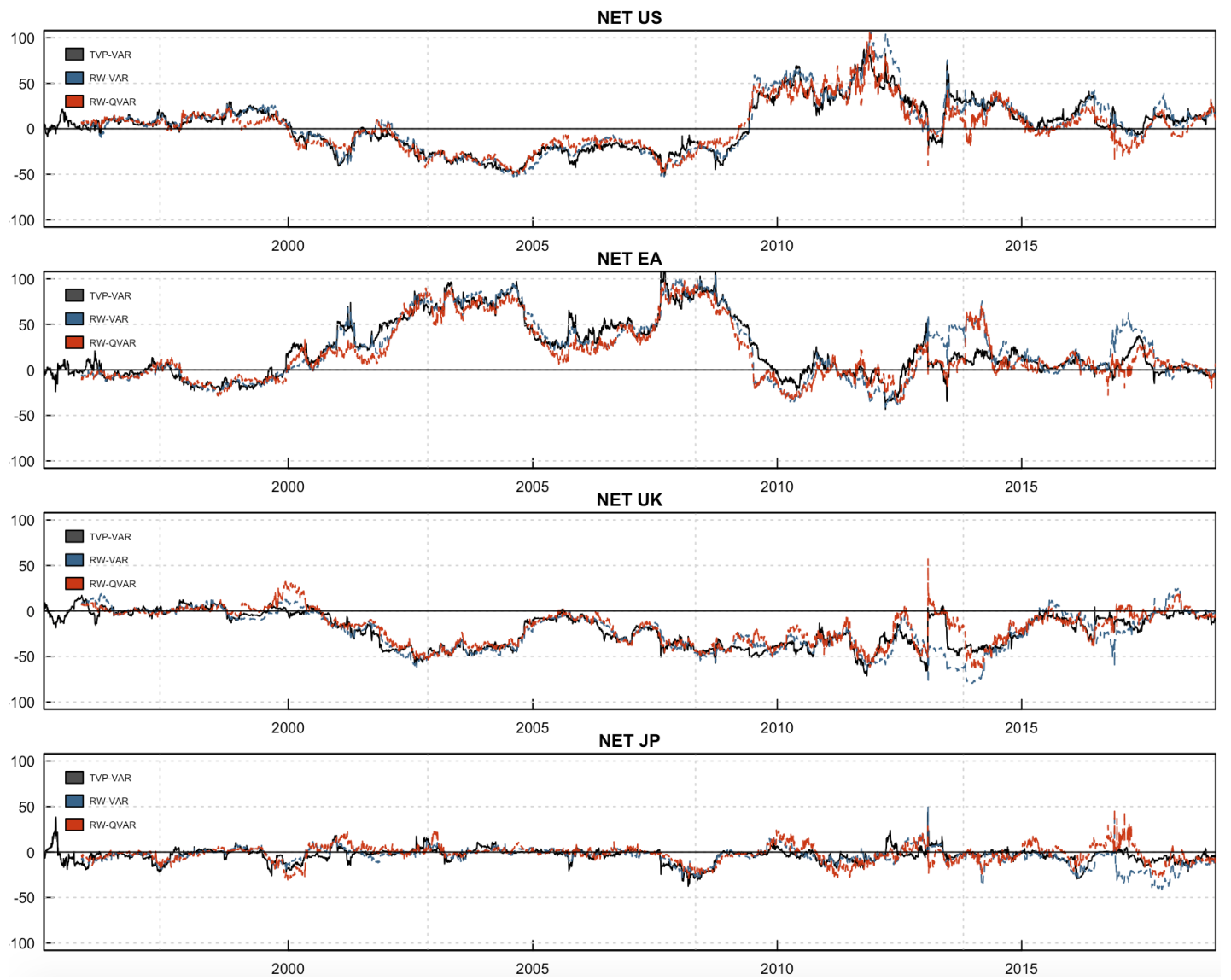

Figure 6: Net Pairwise Directional Connectedness
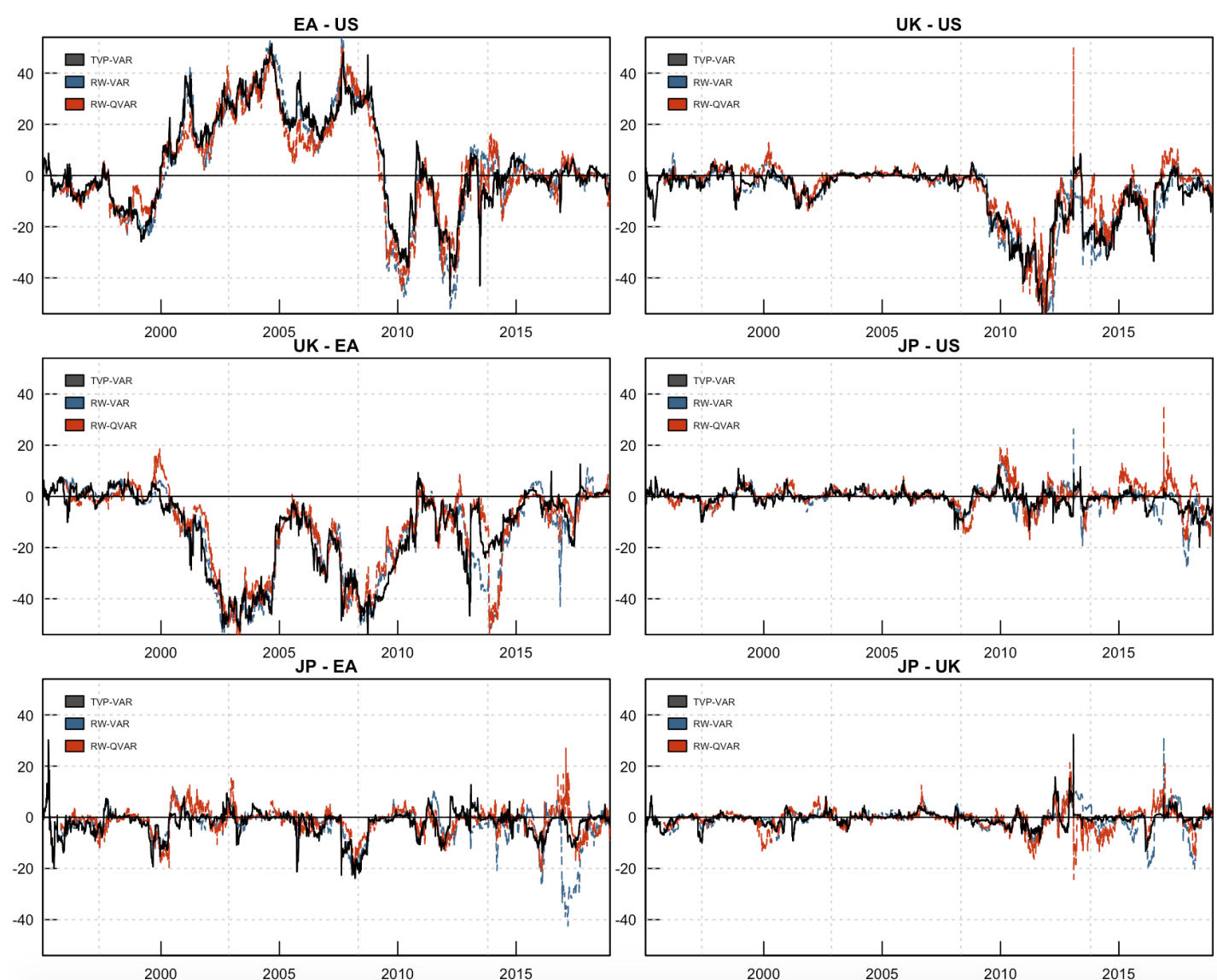
Figure 7: Sensitivity Analyses
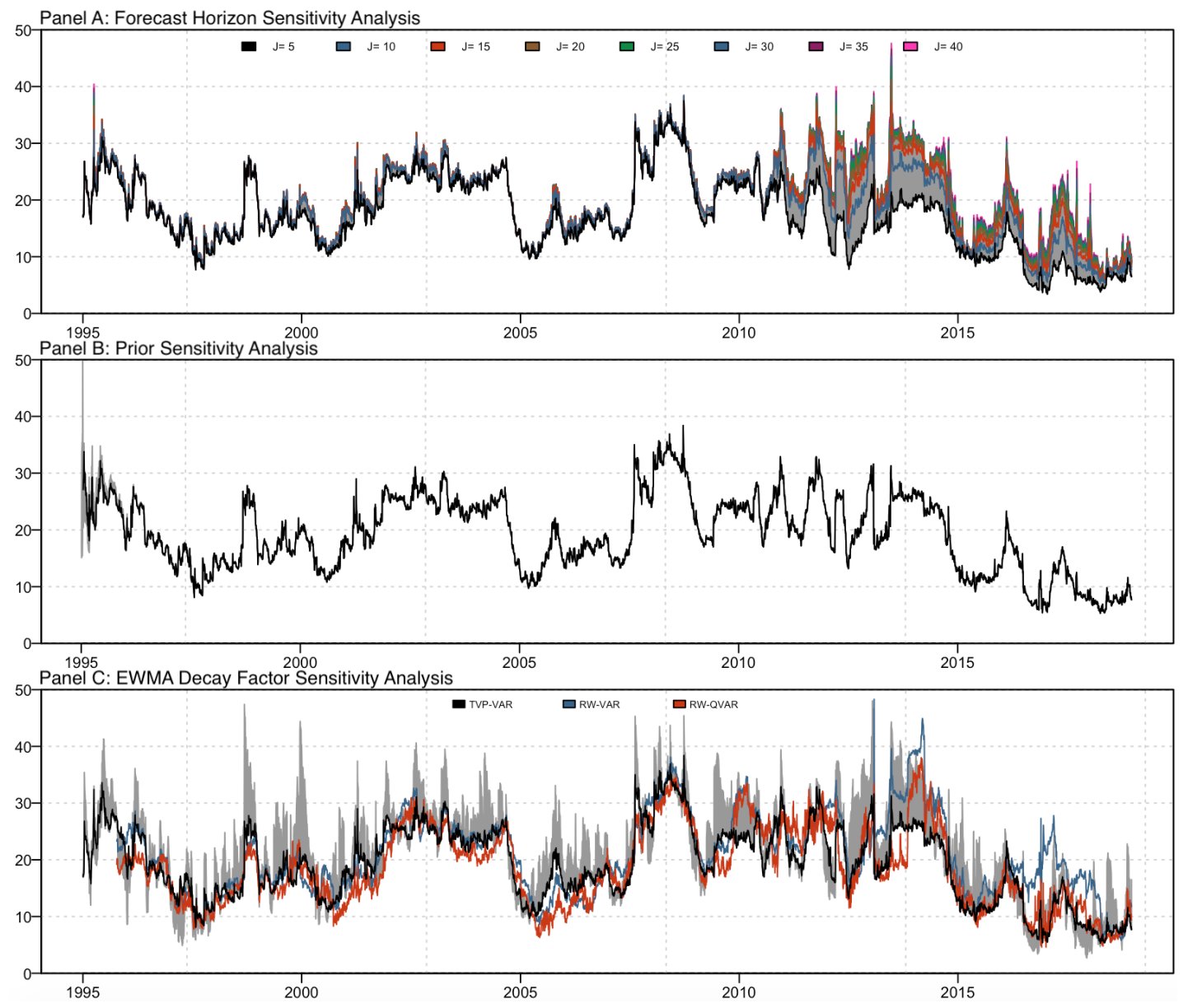

Panel A: Different forecast horizons are used $[5,10,15,20,25,30,35,40]$. Panel B: $\boldsymbol{A}_{0} \sim \mathcal{N}\left(\operatorname{diag}(\mathcal{U}(-1,1), \boldsymbol{V}) \quad \boldsymbol{V}_{i j}=\left\{\begin{array}{l}\frac{0.1}{p^{2}} \text { for own lag } \\ \frac{0.1 \sigma_{i i}}{p^{2} \sigma_{j j}} \text { for lags of variable } j \neq i\end{array}\right.\right.$ Panel C: $\kappa_{1}=[0.95,0.96,0.97,0.98,0.99]$ and $\kappa_{2}=0.99$. 
Table 1: Summary Statistics

\begin{tabular}{lllll}
\hline \hline & US & EU & JP & UK \\
\hline Mean & -0.001 & -0.002 & -0.002 & -0.001 \\
Variance & 0.001 & 0.0003 & 0.0004 & 0.001 \\
Skewness & $-0.183^{* * *}$ & $0.405^{* * *}$ & $0.374^{* * *}$ & $0.861^{* * *}$ \\
Kurtosis & $7.194^{* * *}$ & $8.914^{* * *}$ & $7.792^{* * *}$ & $23.563^{* * *}$ \\
JB & $4,377.7^{* * *}$ & $8,799.2^{* * *}$ & $5,809.1^{* * *}$ & $105,151.7^{* * *}$ \\
ERS & $-22.071^{* * *}$ & $-16.339^{* * *}$ & $-22.306^{* * *}$ & $-20.649^{* * *}$ \\
$Q(10)$ & $4,359.604^{* * *}$ & $12,296.500^{* * *}$ & $6,850.743^{* * *}$ & $5,442.093^{* * *}$ \\
$Q^{2}(10)$ & $2,559.140^{* * *}$ & $8,567.538^{* * *}$ & $3,513.103^{* * *}$ & $2,397.681^{* * *}$ \\
\hline \hline
\end{tabular}

Notes: $* * *, * *, *$ denote significance at $1 \%, 5 \%$ and $10 \%$ significance level; Skewness: D'Agostino (1970) test; Kurtosis: Anscombe and Glynn (1983) test; JB: Jarque and Bera (1980) normality test; ERS: Stock et al. (1996) unit-root test; $Q(10)$ and $Q^{2}(10)$ : Fisher and Gallagher (2012) weighted portmanteau test.

Table 2: Full-Sample Connectedness Table

\begin{tabular}{|c|c|c|c|c|c|}
\hline \multirow[b]{2}{*}{ TO } & \multicolumn{4}{|c|}{ From $(j)$} & \multirow[b]{2}{*}{ FROM } \\
\hline & US & $\mathrm{EU}$ & UK & JP & \\
\hline US & $78.2(77.3)[78.6]$ & $16.4(16.9)[15.2]$ & $3.5(3.5)[3.7]$ & $1.8(2.3)[2.6]$ & $21.8(22.7)[21.4]$ \\
\hline $\mathrm{EU}$ & $10.7(12.2)[10.9]$ & $83.8(82.5)[83.7]$ & $3.5(3.4)[3.1]$ & $2.0(1.9)[2.4]$ & $16.2(17.5)[16.3]$ \\
\hline UK & $11.3(11.6)[9.3]$ & $17.2(18.4)[15.9]$ & $70.0(67.8)[72.8]$ & $1.5(2.2)[2.0]$ & $30.0(32.2)[27.2]$ \\
\hline JP & $2.5(3.2)[2.5]$ & $4.5(5.1)[3.9]$ & $2.0(2.8)[2.8]$ & $91.0(88.9)[90.9]$ & $9.0(11.1)[9.1]$ \\
\hline$\overline{\mathrm{TO}}$ & $24.5(27.0)[22.7]$ & $38.1(40.4)[34.9]$ & $9.0(9.7)[9.5]$ & $5.3(6.3)[6.9]$ & TCI \\
\hline NET & $2.7(4.4)[1.3]$ & $21.9(22.9)[18.6]$ & $-20.9(-22.4)[-17.7]$ & $-3.7(-4.8)[-2.2]$ & $19.2(20.9)[18.5]$ \\
\hline
\end{tabular}

Notes: Values reported are variance decompositions for estimated TVP(200RW)[200RWQ]VAR model. Variance decompositions are based on 10-step-ahead forecasts. A lag length of order 1 was selected by the Bayesian information criterion. 
Table 3: Connectedness Table - Conventional Versus Unconventional Monetary Policy

\begin{tabular}{|c|c|c|c|c|c|}
\hline \multicolumn{6}{|c|}{ Panel A: Conventional Monetary Policy Era (02.01.1995-30.11.2008) } \\
\hline \multicolumn{6}{|c|}{ From $(j)$} \\
\hline TO & US & EU & UK & JP & FROM \\
\hline US & $71.4(71.3)[73.6]$ & $22.1(22.6)[20.1]$ & $4.6(4.4)[4.6]$ & $1.8(1.7)[1.6]$ & $28.6(28.7)[26.4]$ \\
\hline $\mathrm{EU}$ & $8.4(8.9)[7.6]$ & $84.7(85.0)[85.9]$ & $4.7(4.3)[4.1]$ & $2.2(1.8)[2.4]$ & $15.3(15.0)[14.1]$ \\
\hline UK & $6.4(5.8)[5.0]$ & $20.6(21.3)[19.4]$ & $71.9(71.5)[74.3]$ & $1.2(1.4)[1.3]$ & $28.1(28.5)[25.7]$ \\
\hline JP & $2.0(2.0)[1.9]$ & $5.1(4.1)[3.8]$ & $1.6(1.6)[1.6]$ & $91.3(92.3)[92.7]$ & $8.7(7.7)[7.3]$ \\
\hline$\overline{\mathrm{TO}}$ & $16.8(16.7)[14.5]$ & $47.8(48.0)[43.3]$ & $10.6(10.3)[10.3]$ & $5.2(4.9)[5.4]$ & TCI \\
\hline NET & $-11.8(-12.0)[-11.9]$ & $32.5(33.30)[29.2]$ & $-17.2(-18.2)[-15.4]$ & $-3.5(-2.8)[-1.9]$ & $20.2(20.0)[18.4]$ \\
\hline \multicolumn{6}{|c|}{ Panel B: Unconventional Monetary Policy Era (01.12.2008-20.12.2018) } \\
\hline \multicolumn{6}{|c|}{ From $(j)$} \\
\hline TO & US & $\mathrm{EU}$ & UK & JP & FROM \\
\hline US & $87.7(85.1)[85.2]$ & $8.5(9.5)[8.7]$ & $2.0(2.3)[2.4]$ & $1.8(3.0)[3.8]$ & $12.3(14.9)[14.8]$ \\
\hline $\mathrm{EU}$ & $13.8(16.6)[15.2]$ & $82.5(79.2)[80.8]$ & $1.9(2.2)[1.7]$ & $1.8(2.0)[2.3]$ & $17.5(20.8)[19.2]$ \\
\hline UK & $18.0(19.1)[14.9]$ & $12.6(14.6)[11.3]$ & $67.5(63.1)[71.0]$ & $1.9(3.2)[2.8]$ & $32.5(36.9)[29.0]$ \\
\hline JP & $3.3(4.8)[3.2]$ & $3.6(6.3)[4.0]$ & $2.6(4.4)[4.3]$ & $90.5(84.4)[88.5]$ & $9.5(8.2)[11.5]$ \\
\hline $\mathrm{TO}$ & $35.1(40.5)[33.3]$ & $24.7(30.5)[24.0]$ & $6.5(9.0)[8.4]$ & $5.5(8.2)[8.9]$ & TCI \\
\hline NET & $22.8(25.7)[18.5]$ & $7.2(9.6)[4.8]$ & $-26.1(-27.9)[-20.7]$ & $-4.0(-7.9)[-2.6]$ & $17.9(22.0)[18.7]$ \\
\hline
\end{tabular}

Notes: Values reported are variance decompositions for estimated TVP(200RW)[200Q]VAR models. Variance decompositions are based on 10-step-ahead forecasts. In both periods, a lag length of order 1 was selected by the Bayesian information criterion. 